This is the authors postprint version of the article originally published in:

Journal of Experimental Child Psychology (2009) 103(4):516-531 doi: 10.1016/j.jecp.2009.03.009

\title{
Exploring the impact of phonological awareness, visual-spatial working memory, and preschool quantity-number competencies on mathematics achievement in elementary school: Findings from a 3-year- longitudinal study
}

\author{
Kristin Krajewski ${ }^{a}, *$, Wolfgang Schneider ${ }^{\text {b }}$ \\ ${ }^{a}$ German Institute for International Educational Research, D-60486 Frankfurt, Germany \\ ${ }^{b}$ Department of Psychology, Würzburg University, D-97070 Würzburg, Germany \\ * Corresponding author: \\ E-mail address: krajewski@ dipf.de (K. Krajewski)
}

\begin{abstract}
This longitudinal study explored the importance of kindergarten measures of phonological awareness, working memory, and quantity-number competencies (QNC) for predicting mathematical school achievement in third graders (mean age 8;8 years). It was found that the impact of phonological awareness and visual-spatial working memory, assessed at five years of age, was mediated by early QNC, which predicted math achievement in third grade. Importantly, and confirming our isolated number-words hypothesis, phonological awareness had no impact on higher numerical competencies (i.e., when number words had to be linked with quantities; QNC Level II and above), but predicted basic numerical competencies (i.e., when number words were isolated from quantities; QNC Level I), which explained the moderate relationship between early literacy development and the development of mathematical competencies.
\end{abstract}

Keywords: Longitudinal study, visual-spatial working memory, phonological awareness, quantity-number competencies, mathematics, isolated number-words hypothesis 


\section{Introduction}

During the last three decades, numerous longitudinal studies on literacy development were carried out in various countries that all demonstrated the predictive power of phonological information processing skills. In particular, individual differences in early phonological awareness, that is, the ability to analyze the sound structure of oral language, predicted differences in reading and spelling skills in elementary school (e.g., Bradley \& Bryant, 1985; Schneider \& Näslund, 1999; Wagner \& Torgesen, 1987). Moreover, several studies focusing on the early training of phonological awareness were able to show that children trained during the last year of kindergarten outperformed untrained control children in reading and spelling at school, and that training phonological awareness in kindergarten was also successful for children at-risk for dyslexia, that is, children with very low levels of phonological awareness (e.g., Bradley \& Bryant, 1985; Lundberg, Frost, \& Peterson, 1988; Schneider, Küspert, Roth, Visé, \& Marx, 1997; Schneider, Roth, \& Ennemoser, 2000). Undoubtedly, phonological awareness plays an important role for literacy development, regardless of the type of orthography under study (i.e., shallow vs. deep).

\section{Domain-specific precursors of mathematical school achievement}

While it is well-known that relevant precursors of literacy development are already acquired during the preschool and kindergarten years, precursors of mathematical competencies such as quantity-number competencies are not similarly well investigated. According to the available studies, it seems that linking imprecise nonverbal quantity concepts with the ability to count (which develops separately) forms the basis for understanding several major principles of the number system (cf. Resnick, 1989; Okamoto \& Case, 1996; Gersten, Jordan, \& Flojo, 2005; Krajewski \& Schneider, in press; Lemer, Dehaene, Spelke, \& Cohen, 2003). A recently proposed theoretical model (Krajewski, 2008; see also Krajewski \& Schneider, in press) depicts how this linkage might occur and how early mathematical competencies are acquired via three developmental levels, aiming at a deeper understanding of quantity to number-word linkages (see Figure 1). Given that this paper explores the impact of phonological awareness and working memory on the different developmental levels of math competency, relevant features of the theoretical model are described below.

\section{Level I: Number-word sequence isolated from quantities (basic numerical skills)}

Children are born with the capacity to discriminate quantities. As some researchers assume, this implies that infants can already differentiate between discrete quantities (see Antell \& Keating, 1983; Bijeljac-Babic, Bertoncini, \& Mehler, 1993; Huntley-Fenner \& Cannon, 2000; Starkey \& Cooper, 1980; Wynn, 1992; for large numerosities: Xu, Spelke, \& Goddard, 2005). Others believe that infants only differentiate between the spatial extent of quantities but not between discrete amounts (see Clearfield \& Mix, 1999, 2001; Feigenson, Carey, \& Spelke, 2002; Mix, Huttenlocher, \& Levine, 1996, 2002; Rousselle, Palmers, \& Noël, 2004; Simon, Hespos, \& Rochat, 1995; for small numerosities: Xu, Spelke, \& Goddard, 2005). As indicated by the first level of the theoretical model, we assume that children are at least able to differentiate between indiscrete amounts (quantity discrimination). With the acquisition of language, children acquire the ability to discriminate quantities also verbally. When comparing quantities, they use words like "more," "less," or "the same amount" (see Resnick, 1989; protoquantitative comparison schema). Independently, they learn to count (recite number words) beginning at around age two, and thereby already acquire precise number words and the exact number word sequence. However, they do not yet employ these number words to describe quantities (number words still isolated from quantities). As a consequence, verbal abilities such as phonological awareness should be more important for the acquisition of the number-word sequence than visual-spatial abilities. 


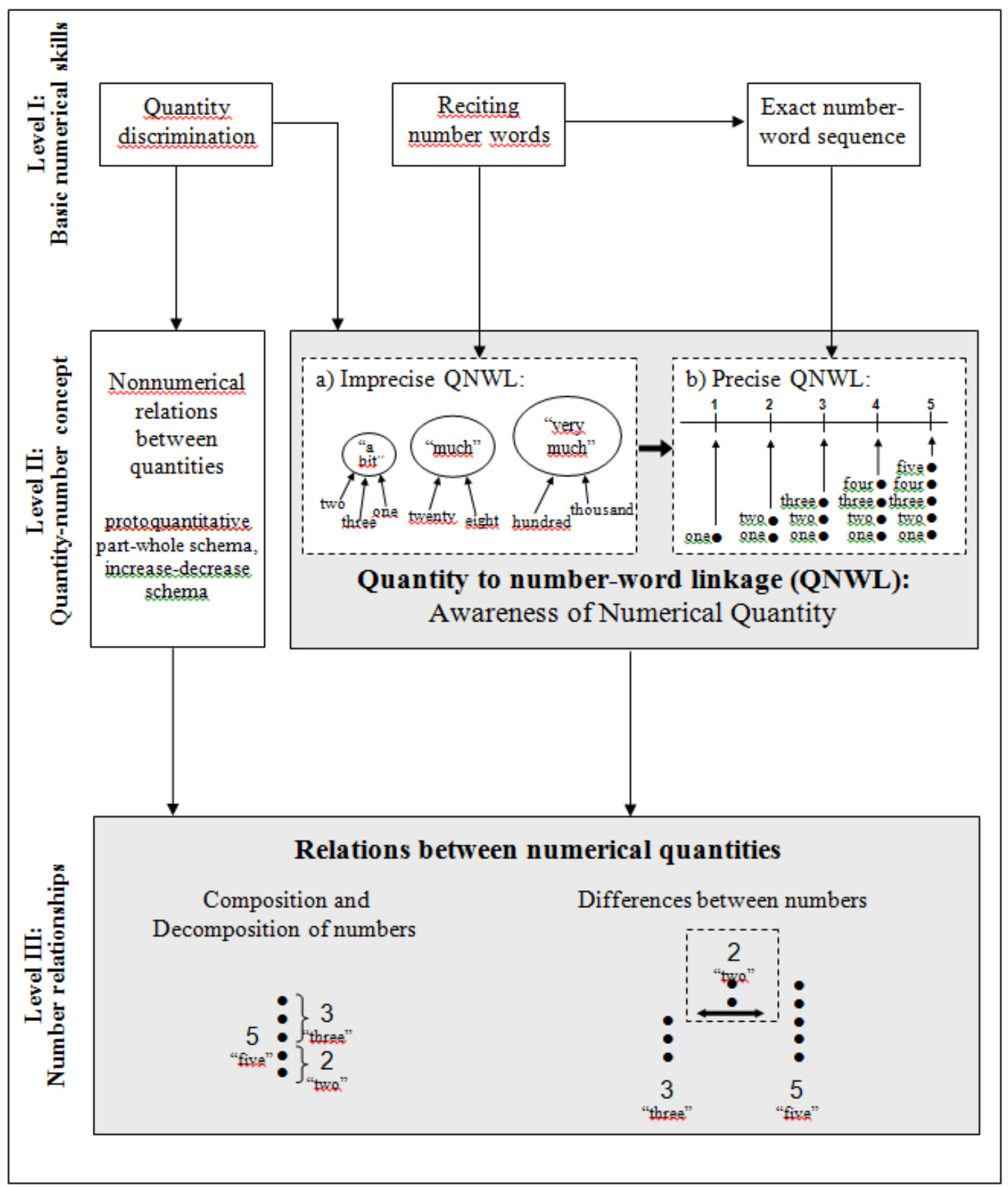

Figure 1: Theoretical model of early arithmetical development (Krajewski, 2008)

\section{Level II: Quantity to number-word linkage (linking number words with quantity)}

Somewhat later, young children become aware that number words are linked to quantities. At this point, they become able to understand the meaning of number words, which enables children to arrange numbers according to their size (see Okamoto \& Case, 1996; Gersten, Jordan, $\&$ Flojo, 2005). The understanding of the linkage between quantities and number words is typically acquired in two phases. First, children develop an imprecise, vague conception of the attribution of number words to quantities, and assign number words to rough quantity-categories (Level IIa: imprecise quantity to number-word linkage). Based on this understanding, children at around age three can already distinguish between number words that are assigned to different rough quantity-categories (e.g. "two" = "a bit", "twenty" = "much", "hundred" = "very much"), because these are discrete from each other. However, during this developmental phase they are not yet able to distinguish between numbers that are assigned to the same quantity category because number words of the same quantity category represent the same amount (e.g., $20=22=$ "much"). The ability to distinguish between adjacent numbers develops gradually when number 
words are also linked to exact quantities (Level IIb: precise quantity to number-word linkage), that means when quantities (exactly enumerated) are precisely arranged to the exact numberword sequence (for linking counting with quantity discrimination see Gersten et al., 2005; Okomato \& Case, 1996). Only now children are able to judge which of two adjoining number words (e.g. 15 and 16) contains "fewer" or "more". As Ansari, Donlan, Thomas, Ewing, Peen, and Karmiloff-Smith (2003) could show with normally developed 3-year-olds, individual differences in visual-spatial working memory become especially important when children have to grasp the cardinality understanding at this developmental level.

Independent of the differentiation of the quantity to number-word linkage, children gather experiences with relations between quantities (without reference to number words). They realize that a quantity can be divided into pieces that, taken together, equal the original quantity (see Resnick, 1989: protoquantitative part-whole schema, from about age four to five), and that quantities change only if something is added or taken away (see Resnick: protoquantitative increase/decrease schema).

\section{Level III: Linking quantity relations with number words (concept of number relationships}

At the highest level of quantity-number competence, the child understands that part-whole relations between quantities can also be represented with precise number words (decomposition of numbers). In addition, the child discovers that the difference between two numerical quantities yields a third numerical quantity (differences between numbers). At this point, children thus arrive at the important insight that the difference between two numbers is another number. In order to understand (non-)numerical relations between quantities (Levels II and III), preschoolers' visual-spatial abilities should take on special importance because the non-verbal representation of quantities seems important to solve such tasks (cf. Rasmussen \& Bisanz, 2005).

There is empirical evidence demonstrating that the described early quantity-number competencies predict later mathematical school achievement (Aunola, Leskinen, Lerkkanen, \& Nurmi, 2004; Koponen, Aunola, Ahonen, \& Nurmi, 2007; Krajewski \& Schneider, in press; Jordan, Kaplan, Locuniak, \& Ramineni, 2007; Passolunghi, Vercelloni, \& Schadee, 2007; Stern, 1997, 1999; von Aster, Schweiter, \& Weinhold-Zulauf, 2007; Weißhaupt, Peucker, \& Wirtz, 2006; see also Gersten, Jordan, \& Flojo, 2005, and Okamoto \& Case, 1996 for the special importance of Levels I and II). Moreover, in studies focusing on children with mathematical learning disabilities, school children showed deficits in these quantity-number competencies (Gaupp, Zoelch, \& Schumann-Hengsteler, 2004; Geary, Hamson, \& Hoard, 2000; Geary, Hoard, Byrd-Craven, \& DeSoto, 2004; Landerl, Bevan, \& Butterworth, 2004). Confirming the special importance of the quantity to number-word linkage, for instance, the 7-year-olds with Williams Syndrome in the study by Ansari, Donlan, Thomas, Ewing, Peen, and Karmiloff-Smith (2003) demonstrated an extremely delay in the understanding of the cardinality principle (Level II), despite the fact that they could recite the number-word sequence (Level I) in the assessed number range almost without errors.

\section{Importance of working memory for the development of literacy and math competencies}

In several longitudinal studies on reading and math development, domain-general predictor variables were included in addition to the specific ones. For instance, indicators of working memory have been identified as potentially relevant unspecific predictors of both literacy and mathematics development in school (see Berg, 2008; Bull, Espy, \& Wiebe, 2008; Geary, Hamson, \& Hoard, 2000; Geary, Hoard, Byrd-Craven, Nugent, \& Numtee, 2007; Hecht, Torgesen, Wagner, \& Rashotte, 2001; Landerl, Bevan, \& Butterworth, 2004; Swan \& Goswami, 1997; Wolf, 1984). Phonological aspects of working memory, in particular, phonological recoding and phonological rehearsal processes as conceptualized in Baddeley's (1986) working 
memory model have been shown to affect subsequent literacy development during elementary school (see Daneman, 1987; Schneider \& Näslund, 1999; Schuchardt, Kunze, Grube, \& Hasselhorn, 2006; Swanson \& Howell, 2001; Wagner \& Torgesen, 1987). Findings of a recent study by Alloway et al. (2005) indicate that the central executive component of Baddeley's model may also affect literacy development, particularly in the case of children at-risk (see also Schuchardt et al., 2006).

Similar relationships with early individual differences in the phonological component of working memory have also been reported for math achievement (Berg, 2008; Rasmussen \& Bisanz, 2005; Hecht, Torgesen, Wagner, \& Rashotte, 2001; but see Lee, Ng, Ng, \& Lim, 2004; Swanson, 2006). Here, effects of the central executive seem particularly strong (Bull, Espy, \& Wiebe, 2008; Geary, Brown, \& Samaranayake, 1991; Geary \& Hoard, 2001; Gersten, Jordan, \& Flojo, 2005; Leather \& Henry, 1994; Lee, Ng, Ng, \& Lim, 2004; Lemaire, Abdi, \& Fayol, 1996; Logie, Gilhooly, \& Wynn, 1994; Passolunghi, \& Siegel, 2004; Passolunghi, Vercelloni, \& Schadee, 2007; Rammelaere, Stuyven, \& Vandierendonck, 2001; Swanson, 2006; Swanson \& Beebe-Frankenberger, 2004; Thomas, Zoelch, Seitz-Stein, \& Schumann-Hengsteler, 2006). In a recent study by Geary, Hoard, Byrd-Graven, Nugent, and Numtee (2007) it was shown that all components of working memory, including the visual-spatial sketch pad, are related to math performance in school. The impact of the visual-spatial sketch pad on math achievement was also confirmed in recent cross-sectional and longitudinal studies (Berg, 2008; Bull, Espy, \& Wiebe, 2008; Simmons, Singleton, \& Horne, 2008; but see Leather \& Henry, 1994; Lee, Ng, Ng, \& Lim, 2004; Seitz \& Schumann-Hengsteler, 2002; Swanson, 2006, for inconsistent results).

\section{Relationships among literacy and math competencies: The role of phonological awareness}

Several studies found substantial intercorrelations between literacy and math competencies in school, ranging between $r=.4$ and .6 (e.g., Berg, 2008; Koponen et al., 2007; Lee et al., 2004; Schneider, 2009). This indicates that similar cognitive competencies influence performance development in these two areas of school achievement, even though the two domains seem quite different from a substantive point of view. Meanwhile several studies addressed the issue which deficits in relevant precursor variables are related to problems in both literacy and math development (e.g., Geary, 1993). As a major finding, these studies not only highlighted the impact of working memory skills, but especially emphasized the role of phonological awareness for subsequent mathematical achievement. In a classic study, Bradley and Bryant (1985) reported that phonological awareness (sound categorization task) assessed in kindergarten not only correlated with reading and spelling $(\mathrm{r}=.50)$, but also with math achievement assessed three years later $(r=.33)$. Similarly, Alloway et al. (2005) found a substantial relationship $(r=$ .49) between phonological awareness (rhyme detection and initial consonant detection) assessed at ages 4 and 5 and mathematical competencies as judged by teachers at the beginning of first grade.

More recently, Koponen, Aunola, Ahonen and Nurmi (2007) reported a synchronic correlation of .58 between phonological awareness (initial sound matching, initial sound naming) and counting abilities in their longitudinal study, and a diachronic correlation of .34 with calculation in Grade 4. Also, findings by Hecht, Torgesen, Wagner, and Rashotte (2001) suggest substantial interrelationships among indicators of phonological awareness (phoneme elision, phoneme segmentation, sound categorization, blending phonemes) and math performance in Grades 2 to 5 , with correlations ranging between $r=.47$ and $r=.56$. In the cross-sectional study by Leather and Henry (1994) $31 \%$ of the variance in arithmetical achievement at seven years of age were predicted by the composite phonological awareness score (initial and final consonant task, blending task, phoneme tapping). Moreover, a longitudinal study by Simmons, Singleton and Horne (2008) showed that phonological awareness scores (rhyme task) assessed at the age of five years predicted reading as well as arithmetic one year later. 
Although there is a lot of support for the relationship between phonological awareness and math achievement, a few studies came up with inconsistent findings. For instance, Durand, Hulme, Larkin, and Snowling (2005) could not confirm this relationship. In their study, phoneme deletion was a unique predictor of individual differences in reading, but did not predict subsequent arithmetic skills. Also, Fuchs, Compton, Fuchs, Paulsen, Bryant, and Hamlett (2005) reported that phonological processing (measured by rapid digit naming, first sound and last sound matching) was a unique determinant of fact fluency but did not predict other aspects of math performance (e.g. story problems). Fuchs, Fuchs, Compton, Powell, Seethaler, Capizzi, Schatschneider, and Fletcher (2006) reported similar results when phonological processing was measured by phonological decoding of pseudowords.

As Simmons and Singleton (2008) state in their weak phonological representations hypothesis, phonological processing deficits will impair aspects of mathematics that involve the manipulation of verbal codes, but will not impair areas of mathematics that are not verbally coded. When transferred to the assumption of different levels in Krajewski's model, a plausible explanation for the correlation between phonological awareness and mathematical school achievement could be seen in an indirect influence of phonological awareness on mathematical school achievement via learning number words and the number-word sequence (basic numerical skills; Level I). Because phonological awareness reflects the ability to differentiate between meaningful segments of the language and to manipulate them, it should facilitate the differentiation and manipulation of single words in the number-word sequence. Accordingly, the number-word sequence should not be used as a string level anymore (,onetwothreefourfive“, see Fuson, 1988), but conceived of as separated number words in a fixed order (,one two three four five "; see Fuson: unbreakable list), an order that even can start without the first elements ("three four five"; see Fuson: breakable list). One major goal of the present study was to explore this assumption in more detail.

\section{Major aims and hypotheses of the present study}

Based on Krajewski's model, we tried to understand the development of mathematical skill and its covariation with other skills pointing out a multicomponential approach, as claimed by Koponen et al. (2007). The following two research questions were examined in this study: A first question concerned the role of working memory, especially the role of the visual-spatial working memory component, for the development of early quantity-number competencies and mathematical school achievement. We assumed that visual-spatial working memory should above all predict higher-level quantity-number competencies (QNC Level II and III), as well as mathematical school achievement (see Bull, Espy, \& Wiebe, 2008; Simmons, Singleton, \& Horne, 2008). According to the developmental model, it is only here that the ability to represent (and interpret) the quantitative information of numbers becomes important. Basic numerical skills (Level I) on the other side should not substantially be predicted by visual-spatial working memory because they do not require the linking of numbers with quantity.

A second major question concerns the impact of early phonological awareness on later mathematical school achievement. More specifically, the question is whether the link is a direct or only an indirect one. Our "isolated number-words hypothesis" assumes that phonological awareness should influence the development of basic numerical skills (i.e., number words isolated from quantities; QNC Level I). However, after controlling for its impact on these basic numerical skills, phonological awareness should not directly predict higher-level competencies (when number words are linked with quantities; QNC Level II and III), and mathematical school achievement. Supporting evidence was found in the longitudinal study by Passolunghi et al. (2007) where only counting skills, but not phonological ability (assessed by first-sound repetition, last-sound repetition, phonemic segmentation) predicted later mathematical achievement. 


\section{Method}

\section{Sample and design of the study}

The study began in September $2004\left(\mathrm{~T}_{1}\right)$ with 108 German pre-schoolers (55 girls, 53 boys) who attended their last year in kindergarten, and lasted until the beginning of Grade $3\left(\mathrm{~T}_{4}\right)$. Informed consent was obtained from the parents. Sample size dropped to 91 by the last measurement point, due to the fact that some children were not enrolled in school, moved away, or dropped out because of illness. Thus the dropout rate was about $16 \%$. At the beginning of the study, children's average age was $5 ; 7$ years $\left(4 ; 11\right.$ - 6;6 years), and at $\mathrm{T}_{4}$ it was $8 ; 8$ years $(8 ; 0$ $9 ; 7$ years). Eight children came from families with an immigrant background, with three children not speaking German at home. All of these children were fluent in German. Children were tested three times within their last year in kindergarten, namely in September 2004 (first measurement point, one year to school; $\mathrm{T}_{1}$ ), January 2005 (second measurement point, eight months to school; $\mathrm{T}_{2}$ ) and July 2005 (third measurement point, two months to school; $\mathrm{T}_{3}$ ). Kindergarten tests were placed in single sessions. At the beginning of Grade 3 (fourth measurement point; $\mathrm{T}_{4}$ ) children took part in the school achievement tests in group sessions.

\section{Materials and procedure}

All three components of working memory (Baddeley, 1986) were investigated at $\mathrm{T}_{1}$ in our study. Both digit-span-forward and digit-span-backward tasks were used, representing measures of the phonological loop (PL) and the central executive (CE), respectively. Here, children had to repeat monosyllabic, single-digit numbers (in the same or the reverse order) that were orally presented at intervals of one second. Scores were identical with the maximal number of digits that could be correctly repeated in a sequence (plus 0.5 , if they correctly repeated both sequences of this number), for example, 2-9 to get a score of 2.0 and 2-9 as well as 4-6 to get a score of 2.5. Furthermore, the visual-spatial sketch pad (visual-spatial working memory) was tested using the matrix task (Wilson, Scott, \& Power, 1987) and the Corsi block task (Milner, 1971). In the matrix task, twenty matrices ( $3 \times 3$ cells, some filled with black color) were presented to the children, five seconds each. Whenever a matrix was blended out, children had to remember and indicate on an empty matrix which cells had been black before (max. score 20). Secondly, in a modified version of the Corsi block task, children had to remember and reconstruct 16 different ways a small figure passed through selected fields on a board (max. score 16).

The short version of the Culture Fair Intelligence Test (CFT 1; Scale 1; Cattell, Weiß, \& Osterland, 1997), consisting of the subtests "classifications", "similarities", and "matrices", was used to tap nonverbal intelligence (max. score 36).

To measure specific precursors of reading and spelling, phonological awareness was assessed at $\mathrm{T}_{1}$. In the Phoneme Synthesis task, children heard a sequence of single phonemes, had to match them to the appropriate word and to pick the corresponding picture out of a choice of four pictures (8 sequences, max. score 8; see Lundberg et al., 1988). To assess rhyming, a task slightly modified after Bradley and Bryant's (1985) Sound Categorization task was used. Here children listened to a sequence of four words and then had to indicate which of these words did not rhyme with the others. Different from the assessment in earlier studies (Schneider, Küspert, Roth, Visé, \& Marx, 1997) in this study the four-word sequence was presented three times backto-back to minimize demands on phonological working memory in this task (10 sequences, max. score 10).

Based on the developmental model described above, quantity-number competencies (QNC) at Level I, II and III were derived as specific mathematical precursor abilities. To find out about basic numerical skills (QNC Level I, number words isolated from quantities; max. 
score 21 ), at $\mathrm{T}_{2}$, first, we assessed how well the children knew the precise number-word sequence forwards and backwards and could identify individual elements within the sequence (Number Word Sequence, QNC Level I; max. score 11). Children needed to recite the precise numberword sequence forward beginning with one at most to 31 (getting a score of 1 for correctly reciting up to 10 , a score of 2 for reciting up to 20 , a score of 3 for reciting up to 30 , and a score of 4 for reciting above 30) and needed to recite it backward from five (getting a score of 1 for correctly reciting) as well as to name three subsequent number words after a designated one (namely 5, 9, 18; max. score 3) and three number words preceding a given number (namely 3, 8, 12; max. score 3). Second, in the Arabic-numbers task at QNC Level I children had to name the Arabic numerals from 1 to 20 that were presented to them in random order. They received half a point for correctly naming each of them (max. score 10).

QNC Level II was measured at $\mathrm{T}_{3}$, using three different tasks (max. score 18). In the quantity-comparison task (Level II; max. score 3) our participants saw small wooden figurines in two parallel rows next to each other that were introduced as children standing on two cash desks to get in an swimming pool. Although the number of objects differed between the rows ( 5 and 6 figurines), the rows were of identical length. Children had to compare the number of the figurines ("Can you tell me in which row are more children, or are as many in this one as in this one?"). Second, in an invariance task six figurines stood in one row. They were then shoved by the experimenter, and in the process pushed together ("Children now are in a hurry and want to speedily arrive in the swimming pool. That's why they shove and push together."). Participants then had to indicate whether there were more, less or still the same number of children as before? Third, in another invariance task, there were two parallel rows next to each other, each with six figurines and with the same spatial length ("Here are other children queueing at a cash desk, coming along with their siblings. Their siblings queue at the other cash desk. This is the sibling of this child, this the sibling of this child ... Now only the siblings are in a hurry and want to speedily arrive in the swimming pool. That's why they shove in their row and push together."). Participants had to whether there were more, less or still the same number of siblings as the number of children in the first row. In all three variations of the quantity-comparison task children were allowed (but not encouraged) to count whenever they wanted.

In the quantity to number-word linked seriation task (Level II; max score 7), children saw several beetles on a sheet that were arranged in a row with one beetle missing. Each beetle had spots on its back. The number of spots determined the position in the row (the first beetle had one spot, the second beetle two spots, etc.). In three different experimental trials, children were presented with an incomplete sequence, where one of the beetles was missing. Children's test was to select the missing beetle out of a choice of five beetles and to insert it correctly in the row. After inserting, children also had to indicate, which of the beetles had the same age as the child, which beetles were younger and which were older, assuming that the number of spots on the back tells us the age of the beetle.

In the number-word comparison task (Level II; max. score 4), children had to decide which of two number words represented "more" or "less" (5-3, 4-6, 12-11, 15-17). To prove quantity to number-word linkage (Level II; max. score 4) last but not least the children had to match quantities (three, five dots) to the corresponding Arabic numerals and to match Arabic numerals $(4,7)$ to the corresponding quantities. To test QNC Level III tasks (max. score 11) at $\mathrm{T}_{3}$, children had to determine the numerical differences between three pairs of dot arrangements (max. score 3). Moreover, children had to solve eight word problems with concrete material (marbles), for instance "You have six marbles. I have four marbles. How many more marbles I still have to get to have as many marbles as you?" (max. score 8).

At the beginning of Grade $3\left(\mathrm{~T}_{4}\right)$, children's school achievement in mathematics and literacy was assessed. To test mathematical school achievement, the German Mathematics test for second grade was used in a group test arrangement (DEMAT 2+, Krajewski, Liehm, \& Schneider, 2004; max score 36). This test is based on a curriculum representative for all German 
states, and investigates competencies in arithmetic (e.g. addition, subtraction, multiplication), applied mathematics, and geometry that children should be able to master after finishing second grade. Tasks were presented in a booklet in Arabic notations, except geometry task in figurative representation and word problems in written language. Each subtest was introduced orally and word problems were additionally read loud by the experimenter. Although there was a time limit for each subtest, the measure cannot be conceived of as a speed test because almost all children solved the subtests completely in time. Spelling was measured by the German Spelling Test for first and second grade (DERET 1-2, Stock \& Schneider, 2008). Here, children had to write a text dictation consisting of 53 words that most children were supposed to master after finishing second grade (max. score 53). Reading comprehension was assessed using a standardized test (ELFE, Lenhard \& Schneider, 2006), where children had to read short text passages and then to answer specific questions related to the passages (max. score 20).

\section{Results}

Descriptive statistics are listed in the lower section of Table 1 . Reliability scores of the tasks ranged between .67 and .94, thus indicating sufficient to good internal consistency. As can be seen from the Kolmogorov Smirnov Z-tests, the assumption of normal distribution was accepted for all tasks except the digit span forward $(Z=1.8 ; p<.01)$, digit span backward $(Z=$ $2.8 ; p<.01)$, Arabic numerals $(Z=2.2 ; p<.01)$ and the school spelling test $(Z=1.8 ; p<.01)$.

Correlational analyses

In a first step, intercorrelations among the various predictor variables assessed in kindergarten and literacy and math achievement assessed at the beginning of Grade 3 were analyzed (see upper section in Table 1). Both synchronic and diachronic correlations were considered in order to come up with a comprehensive picture of interrelationships between the literacy and math domains.

Synchronic correlations were analyzed for the predictor and criterion variables. As to the latter, math performance as indicated by the DEMAT 2+ correlated with spelling assessed by the DERET 1-2 with $r=.59(p<.01)$ and with reading comprehension assessed by the ELFE with $r$ $=.56(p<.01)$, respectively, indicating substantial relationships, even though there was a ceiling effect in the spelling test (see Table 1). Interestingly, the correlations between specific math predictors (number-word sequence and QNC II+III) and the specific literacy predictor (total phonological awareness) assessed in kindergarten were of comparable size $(r=.52 ; p<.01$ and $r$ $=.51 ; p<.01$, respectively).

As can be seen from Table 1, the diachronic relationships between specific predictors of literacy (phonological awareness) and math (QNC) were not only substantial for their target criterion but also for the theoretically unspecific criterion. That is, the relationship between phonological awareness and spelling as well as that between phonological awareness and reading comprehension was of similar size (.54 and .52, respectively) to that between phonological awareness and math performance $\left(.48 ; Z_{\text {spelling/math }}=0.5 ; p>.05 ; Z_{\text {reading/math }}=\right.$ 


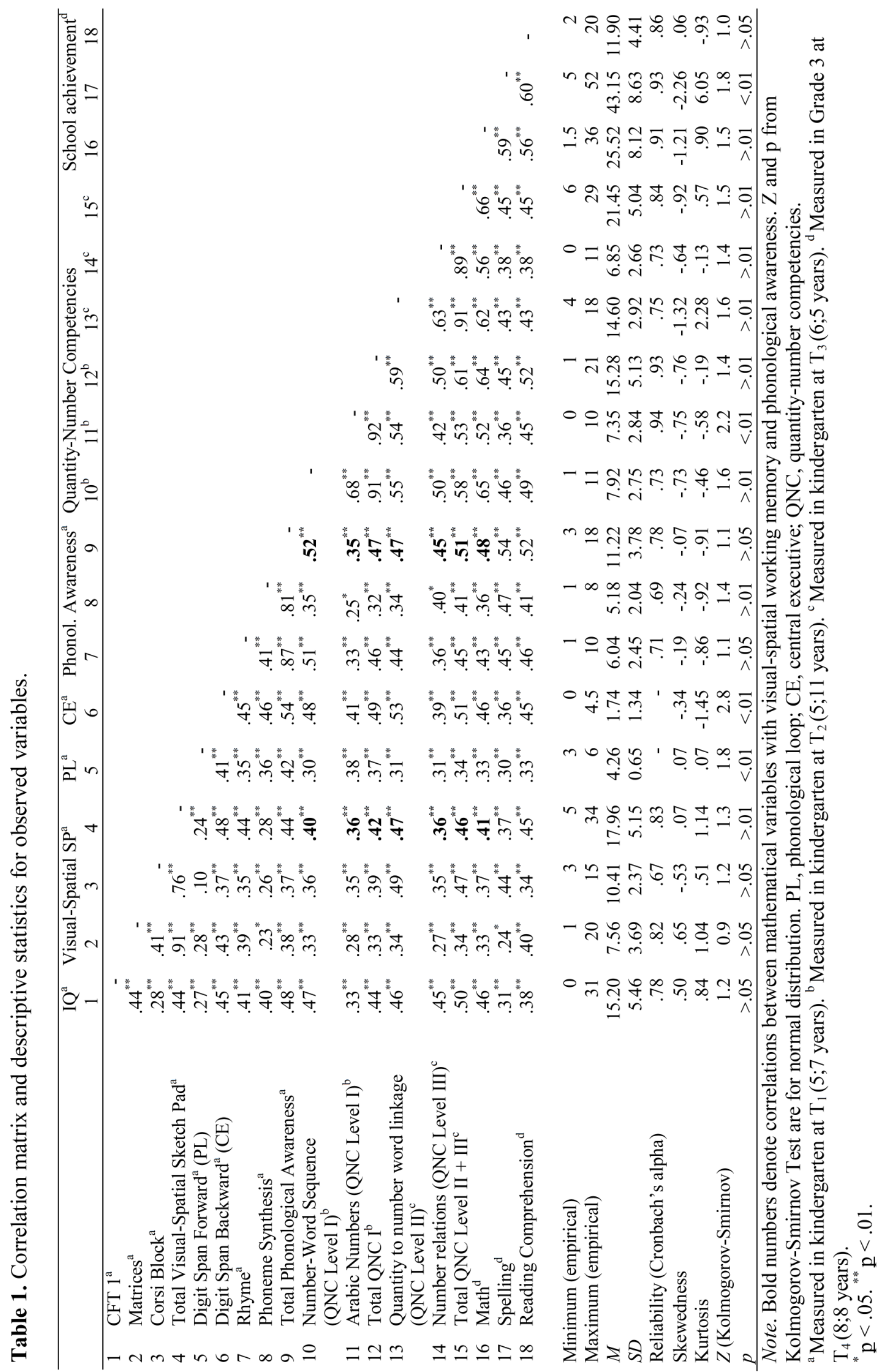


$0.4 ; p>.05)$. Also, the relationship between QNC I and math performance (.65) was not statistically different from that between QNC I and reading comprehension $(r=.49 ; Z=1.6 ; p>$ $.05)$, but it was different from that between QNC I and spelling $(r=.46 ; Z=1.8 ; p<.05)$. However, the correlation between QNC II+III and math performance (.66) differed significantly from that between QNC II+III and spelling as well as reading comprehension $\left(r_{N C 23 / \text { Spelling }}=\right.$ $\left.r_{Q N C 23 / \text { Reading }}=.45 ; Z=2.0 ; p<.05\right)$.

Moreover, the correlations between phonological awareness and math school achievement (.48) were not statistically different from the correlation between phonological awareness and quantity-number competencies assessed in kindergarten $(\mathrm{r}=.47$ and .51 for QNC I and QNC II+III, respectively). The same was true for the diachronic correlations between math achievement in school and the predictor variables intelligence, visual-spatial sketch pad, phonological loop and central executive. The size of these correlations ranged between .33 and .46 and thus was comparable to that of the correlations obtained between quantity-number competencies assessed in kindergarten and intelligence, visual-spatial sketch pad, phonological loop, and central executive, respectively, that ranged between .34 and .51 .

\section{Impact of visual-spatial sketch pad and phonological awareness on early QNC and math at school}

The analyses above showed that correlational patterns among mathematical competencies, working memory skills as well as phonological awareness were similar for school and kindergarten measures. In a second step of analysis, we explored whether an direct impact of phonological awareness on school math performance, as already indicated by several studies (see Alloway et al., 2005; Aunola et al., 2004; Hecht et al., 2001; Koponen, Aunola, Ahonen, \& Nurmi, 2007; Leather \& Henry, 1994; Simmons, Singleton, \& Horne, 2008) would prove stable when QNC skills as specific predictors of math performance were included in a causal model. Moreover, we were interested in exploring whether phonological awareness and visual-spatial working memory would contribute differently to the prediction of the different QNC skills and the school variable. A structural equation model representing the interrelations among visualspatial working memory and phonological awareness with quantity-number competencies was specified and tested. The phonological loop and central executive were not included in the latent variable model because only one indicator each was available to represent these variables. According to our assumptions, QNC Level-I competencies should predict QNC at higher levels (when number words are linked with quantity; see Krajewski, 2008; Passolunghi et al., 2007), and these should predict later mathematical achievement in Grade 3 (see Gersten et al., 2005; Jordan et al., 2007; Koponen et al., 2007; Stern, 1999). We expected early phonological awareness (measured at $\mathrm{T}_{1}$ ) to predict the development of QNC Level-I competencies (at $\mathrm{T}_{2}$ ), but not to predict higher levels of QNC (isolated number-words hypothesis). Higher levels of QNC (at $\mathrm{T}_{3}$ ) and also Grade 3 math performance (at $\mathrm{T}_{4}$ ) should only be predicted by the visual-spatial sketch pad measured at $\mathrm{T}_{1}$ (cf. Berg, 2008; Bull, Espy, \& Wiebe, 2008; Simmons, Singleton, \& Horne, 2008).

In the initial model, all paths from visual-spatial sketch pad and phonological awareness to QNC Level I, QNC Level II+III and mathematics Grade 3 were estimated. Table 2 shows the respective measurement model, indicating the factor loadings of the various indicators on the respective latent variables, together with several indicators of model fit. As can be seen from Table 2 (initial model) the size of factor loadings was satisfactory in general, ranging between $\lambda$ $=.55$ und $\lambda=.95$, which suggests that the various constructs were well represented by the observed indicators. 
Table 2. Factor loadings of measurement model and fit of models

\begin{tabular}{|c|c|c|c|}
\hline \multirow{2}{*}{$\begin{array}{l}\text { Construct and measurement } \\
\text { point }\end{array}$} & \multirow[t]{2}{*}{ Indicators } & \multicolumn{2}{|c|}{ Factor loadings } \\
\hline & & $\begin{array}{l}\text { Initial } \\
\text { Model }\end{array}$ & $\begin{array}{c}\text { Final } \\
\text { Model } \\
\text { (Fig. 2) }\end{array}$ \\
\hline \multirow[t]{2}{*}{ Visual-Spatial Sketch Pad $\left(\mathrm{T}_{1}\right)$} & Matrices & .59 & .59 \\
\hline & Corsi Block & .70 & .69 \\
\hline \multirow[t]{2}{*}{ Phonological Awareness $\left(\mathrm{T}_{1}\right)$} & Rhyme & .75 & .73 \\
\hline & Phoneme Synthesis & .55 & .54 \\
\hline Quantity-number competencies & Number-Word Sequence & .90 & .90 \\
\hline Level I $\left(\mathrm{T}_{2}\right)$ & Arabic Numbers & .75 & .75 \\
\hline Quantity-number competencies & Level II & .86 & .86 \\
\hline Level II/III $\left(\mathrm{T}_{3}\right)$ & Level III & .74 & .74 \\
\hline \multirow[t]{2}{*}{ Mathematics at School $\left(\mathrm{T}_{4}\right)$} & DEMAT $2+$ odd subs & .95 & .95 \\
\hline & DEMAT $2+$ even subs & .92 & .93 \\
\hline \multirow[t]{3}{*}{ Index of model fit } & & \multicolumn{2}{|c|}{ Data fit for } \\
\hline & & Initial & Final \\
\hline & & Model & $\begin{array}{r}\text { Model } \\
\text { (Fig. 2) }\end{array}$ \\
\hline$\chi^{2}$ & & 23.0 & 23.8 \\
\hline $\mathrm{df}$ & & 25 & 29 \\
\hline $\mathrm{p}$ & & .58 & .74 \\
\hline CFI & & 1.0 & 1.0 \\
\hline RMSEA & & $<.01$ & $<.01$ \\
\hline
\end{tabular}

Note. For all indicators, $p<.01$.

Overall, in the initial model the correlation between visual-spatial working memory and phonological awareness was $.73(p<.01)$, indicating a strong relationship between these two constructs at the age of five. About $34 \%$ of the differences in QNC Level I were explained by differences in phonological awareness $(\beta=.58, p=.050)$. In comparison, the visual-spatial sketch pad did not significantly predict QNC Level I $(\beta=.17, p>.05)$. Although phonological awareness and visual-spatial working memory positively affected QNC Level II/III, their respective paths were not significant $(\beta=.13$ and $\beta=.39$, respectively, all $p$ 's $>.05)$.

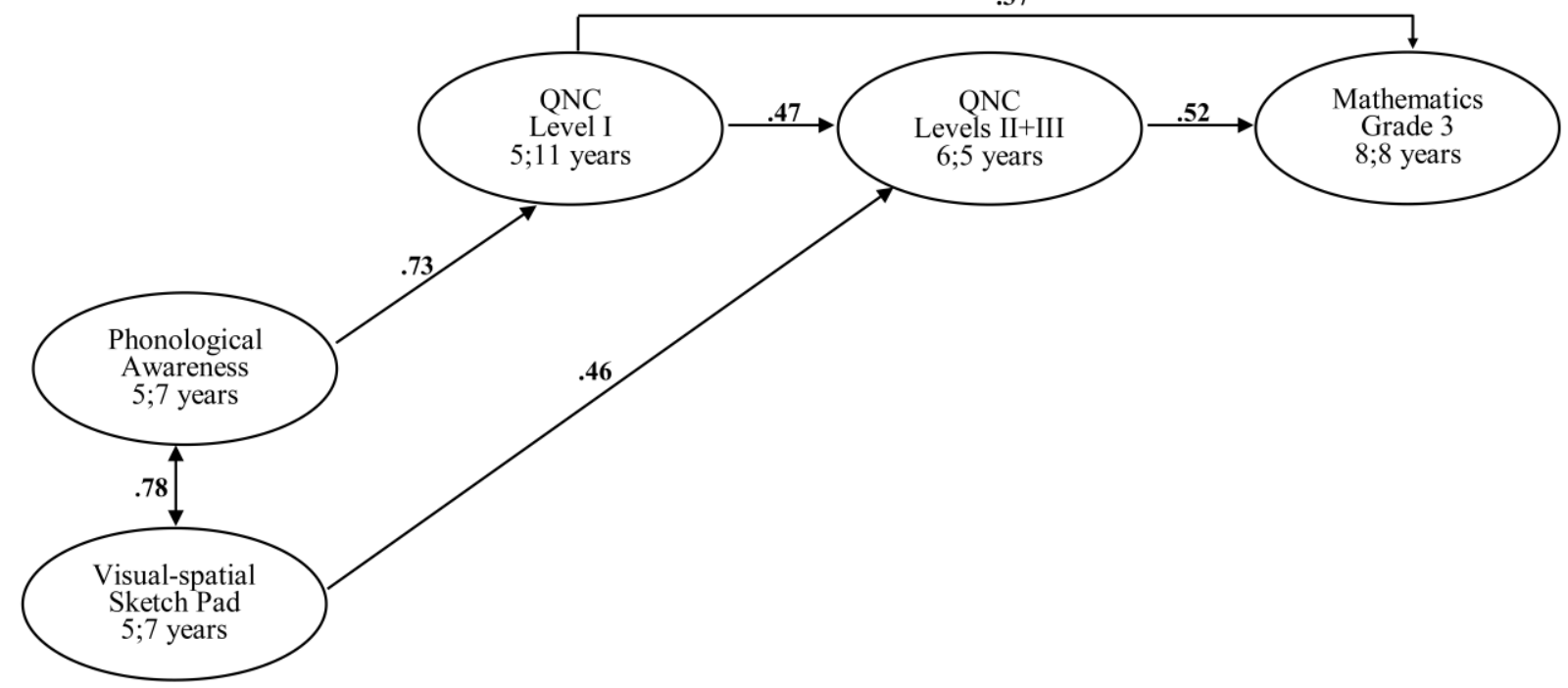

Figure 2: The impact of visual-spatial sketch pad and phonological awareness on lower and higher early quantitynumber competencies assessed in kindergarten and mathematical school achievement in Grade 3 (QNC - quantitynumber competencies; results from final model) 
In line with the developmental model depicted in Figure 1, QNC Level I accounted for about $18 \%$ of the variance in subsequent QNC Level II/III $(\beta=.42, p<.01)$, which in turn predicted about $32 \%$ of the differences in mathematical achievement in Grade 3 ( $\beta=.57, p<$ $.05)$. Moreover, individual differences in QNC-I skills accounted for another $17 \%$ of the variance in Grade 3 math performance $(\beta=.41, p<.05)$. Neither visual-spatial sketch pad $(\beta=-.00, p>$ $.05)$, nor phonological awareness $(\beta=-.10, p>.05)$ contributed significantly to the prediction of Grade 3 math performance when QNC skills were included in the model. As can be seen from Table 2, the causal model did fit the data well $\left(\mathrm{Chi}^{2}[25]=23.0, p=.58 ; C F I=1.0 ; R M S E A<\right.$ .01 ). Assessment of outliers (squared Mahalanobis distance) showed no evidence that any of the observations should be treated as outliers under the assumption of normality (for all $p>.01$ ).

In a second step of path analysis, the four paths with negligible coefficients $(\beta$ 's $<.17 ; p$ 's $>.5)$ were set to zero, and the reduced model was estimated. Given that model fit did not decrease $\left(C h i^{2}[4]=0.75, p=.95\right.$, see also the final model column in Table 2$)$, this model was chosen as the final one, and is shown in Figure 2. Interestingly, the paths from phonological awareness to QNC Level I and from visual-spatial sketch pad to QNC Level II/III became significant $(p<.01)$ in this restricted model.

\section{Discussion}

The major aim of the presented study was to investigate the respective roles of visualspatial working memory (visual-spatial sketch pad) and phonological awareness for school achievement in mathematics. In particular, we were interested in the issue whether influences of the visual-spatial sketch pad and phonological awareness on mathematical school achievement should be conceptualized as indirect (i.e., mediated by different levels of preschool QNC in Krajewski's developmental model), or whether early visual-spatial working-memory and phonological awareness skills also directly account for variance in the mathematical school achievement. More specifically, we addressed the issue whether visual-spatial sketch pad and phonological awareness reliably influence different levels of mathematical precursors such as basic numerical skills (i.e., when number words are not linked with quantities; QNC Level I) and quantity to number-word linkage (QNC Level II and above), which in turn should have an impact on math achievement in school.

In a first step of analysis, we were able to replicate core findings of previous longitudinal studies that found substantial correlations not only between early quantity-number competencies and math performance in school (see Aunola et al., 2004; Gersten et al., 2005; Jordan et al., 2007; Koponen, Aunola, Ahonen, \& Nurmi, 2007; Krajewski \& Schneider, in press; Passolunghi, et al., 2007; Stern, 1997, 1999), but also between early phonological awareness and math school performance (e.g., Alloway et al., 2005; Bradley \& Bryant, 1985; Hecht et al., 2001; Koponen, Aunola, Ahonen, \& Nurmi, 2007; Leather \& Henry, 1994; Simmons, Singleton, \& Horne, 2008). The latter were comparable in size with correlations between phonological awareness and subsequent literacy achievement in school found in studies on literacy development (e.g., Schneider \& Näslund, 1999). These findings confirm the assumption that phonological awareness is a domain-general precursor variable of school achievement rather than a domain-specific precursor variable of only subsequent literacy development in school. Furthermore, our findings illustrate that there are close relationships between literacy development and math development from the early preschool years on. The same was true for the synchroneous relationships between math development and both intelligence and the three components of working memory skills (visual-spatial sketch pad, phonological loop and central executive) that were of comparable size in preschool and school.

However, even though moderate correlations between preschool phonological awareness and visual-spatial working memory on the one hand and mathematical school achievement on the other hand could be found, these preschool abilities had no direct influence on mathematical 
school achievement, as indicated by the outcome of causal modeling analysis. As shown in Figure 2, we could confirm our isolated number-words hypothesis, indicating that differences in phonological awareness substantially predicted individual differences in QNC Level I skills (number words not linked with quantities). However, in contrast to findings in other relevant studies that did not differentiate among quantity-number competencies, phonological awareness did neither directly contribute to the prediction of higher-order quantity-number competencies (number words linked with quantity; QNC Level II and above), nor to the prediction of math competencies in school (see also Fuchs et al, 2005; Fuchs et al., 2006; Durand et al., 2005). This finding confirms the assumption that although phonological awareness facilitates the acquisition of QNC Level-I skills (e.g., learning the precise number-word sequence), it seems less relevant for the formation of higher-order mathematical competencies that require the conceptual understanding of linking quantity information with number words and their Arabic notations (Level II and III in Krajewski's model; cf. Gersten, Jordan, \& Flojo, 2005; Okamoto \& Case, 1996; Resnick, 1989).

Consequently, phonological awareness is a necessary but not sufficient prerequisite for the development of mathematical understanding. Furthermore, deficits in phonological awareness should not only cause a delay in literacy development but also a delay in mathematical development. This may result in mathematical disabilities covariing with reading disabilities, a phenomenon that Geary (1993) describes as the semantic memory subtype.

Interestingly, phonological awareness had a strong relationship with visual-spatial working memory assessed in kindergarten. Moreover, as was found for phonological awareness, the visual-spatial component of working memory had no direct impact on math competencies in school, but exerted an indirect influence on school achievement mediated by higher-order domain-specific precursor variables such as the understanding of quantity to number-word linkage at QNC Level II and III (cf. Geary et al., 2007; Berg, 2008; Bull, Espy, \& Wiebe, 2008; Simmons, Singleton, \& Horne, 2008). Consequently, the visual-spatial sketch pad seems particularly relevant when the task is to create the link from number words to quantities (cf. Ansari, Donlan, Thomas, Ewing, Peen, \& Karmiloff-Smith, 2003). This finding is in line with the notion that at this QNC level non-verbal representations of quantities play an important role (cf. Rasmussen \& Bisanz, 2005). Thus it could be that the mathematical disabilities characterizing the visual-spatial subtype described by Geary (1993) constitute deficits in the representation and interpretation of numerical information (that are not associated with reading disabilities) which just start at QNC Level II, where number words have to linked with visualspatial represented quantities. In contrast, the mathematical disabilities of Geary's semantic memory subtype (see above) probably already begin at QNC Level I.

Our findings only partially confirm the "weak phonological representations hypothesis" by Simmons and Singleton (2008) stating that phonological processing deficits should impair all aspects of mathematics that involve the manipulation of verbal codes, and should not impair areas of mathematics that are not verbally coded. That is, our results indicate that deficits in phonological awareness impair the acquisition of verbal codes that are needed for numerical processing at an early developmental stage. However - if this is controlled for - these deficits do not directly impair higher numerical processing (only indirectly via the automation of numberword sequence), even in the case that other verbal coding procedures should be necessary for the specific numerical processing (e.g., verbally mediated strategies). This leads to the rather optimistic assumption that the impact of deficits in phonological awareness on mathematical impairment can be compensated for very early in mathematical development. Even at kindergarten age, training in learning and manipulating the precise number-word sequence by heart (e.g., forwards and backwards, identifying subsequent and preceding number words, matching number words with their Arabic notations) probably prevents mathematical difficulties typical of Geary's semantic memory subtype, mainly because basic numerical skills (QNC I) seem to be the source of their impairments. 
Summarizing our results, one of the major new insights of this study concerns the central role of phonological awareness for the acquisition and automation of the number-word sequence, but its negligible direct influence on higher-order quantity-number skills that reflect a conceptual understanding of the quantity to number-word linkage. Phonological awareness and the visualspatial component of working memory assessed at an early stage in kindergarten directly influenced math-specific precursor variables assessed a few months later and also showed moderate indirect effects on math performance in school. This finding illustrates that individual differences in phonological awareness and the visual-spatial sketch pad influence the development of math competencies from an early point in time on, actually long before formal schooling begins. Given the importance of phonological awareness for the development of math and literacy in school, it seems important to train this ability as early as possible whenever pronounced deficits are diagnosed. Obviously, young children with impaired phonological awareness (e.g., lack of rhyming skills) seem at risk for developing both math and reading problems. Ideally, such a training of phonological awareness should be combined with training basic numerical skills to facilitate the differentiation and manipulation of single words in the number-word sequence (cf. Fuson, 1988). The fact that correlations between literacy and math development in school as well as in preschool were found to be substantial in our study further confirms this position. On the other hand, however, influences of the visual-spatial sketch pad seem to be restricted to math development at higher levels (see Figure 2). Children with specific deficits in this working memory component but normal phonological awareness skills may develop specific math problems that start with the linking of number words and their Arabic notations to quantities (QNC Level II), but that are not accompanied by difficulties in the reading and spelling domains. Training in linking number words with quantities probably prevents mathematical difficulties typical of Geary's visuospatial subtype, mainly because deficits in visual-spatial working memory cause deficits in the representation and linking of numerical quantities to number words (QNC II), which in turn seems to be the source of their mathematical impairments. Given that this assumption cannot be tested based on our data, further research is needed to address this hypothesis.

\section{References}

Alloway, T.P., Gathercole, S.E., Adams, A.-M., Willis, C., Eaglen, R., \& Lamont, E. (2005). Working memory and phonological awareness as predictors of progress towards early learning goals at school entry. British Journal of Developmental Psychology, 23, 417-426.

Ansari, D., Donlan, C., Thomas, M.S.C., Ewing, S. A., Peen, T., \& Karmiloff-Smith, A. (2003). What makes counting count? Verbal and visuo-spatial contributions to typical and atypical number development. Journal of Experimental Child Psychology, 85, 50-62.

Antell, S.E., \& Keating, D.P. (1983). Perception of numerical invariance in neonates. Child Development, 54, 695701.

Aunola, K., Leskinen, E., Lerkkanen, M-K., \& Nurmi, J-E. (2004). Developmental dynamics of mathematical performance from preschool to grade 2. Journal of Educational Psychology, 96, 699-713.

Baddeley, A. (1986). Working Memory. Oxford: Oxford University Press.

Berg, D.H. (2008). Working Memory and arithmetic calculation in children: The contributory roles of processing speed, short-term memory, and reading. Journal of Experimental Child Psychology, 99, 288-308.

Bijeljac-Babic, R. Bertoncini, J., \& Mehler, J. (1993). How do four-day-old infants categorize multisyllabic utterances? Developmental Psychology, 29, 711-721.

Bradley, L., \& Bryant, P. (1985). Rhyme and reason in reading and spelling. Ann Arbor: The University of Michigan Press.

Bull, R., Espy, K., \& Wiebe, S. A. (2008). Short-term memory, working memory, and executive functioning in preschoolers: Longitudinal predictors of mathematical achievement at age 7 years. Developmental Neuropsychology, 33, 205-228.

Cattell, R.B., Weiß, R.H., \& Osterland, J. (1997). Grundintelligenztest Skala 1 (CFT 1) (5th ed.). Braunschweig: Westermann.

Clearfield, M.W., \& Mix, K.S. (1999). Number versus contour length in infants`discrimination of small visual sets. Psychological Science, 10, 408-411. 
Clearfield, M.W., \& Mix, K.S. (2001). Amount versus number: Infant's use of area and contour length to discriminate small sets. Journal of Cognition and Development, 2, 243-260.

Daneman, M. (1987). Reading and working memory. In J.R. Beech \& A.M. Colley (Eds.), Cognitive approaches to reading (pp. 57-86). Chichester: Wiley.

Durand, M., Hulme, C., Larkin, R., \& Snowling, M. (2005). The cognitive foundations of reading and arithmetic skills in 7- to 10-year-olds. Journal Experimental Child Psychology, 91, 113-136.

Feigenson, L., Carey, S., \& Spelke, E. (2002). Infants`discrimination of number vs. continuous extent. Cognitive Psychology, 44, 33-66.

Fuchs, L. S., Compton, D. L., Fuchs, D., Paulsen, K., Bryant, J. D., \& Hamlett, C. L. (2005).The prevention, identification and cognitive determinants of maths difficulty. Journal of Educational Psychology, 97, 493513.

Fuchs, L. S., Fuchs, D., Compton, D. L., Powell, S. R., Seethaler, P. M., Capizzi, A. M., Schatschneider, C., \& Fletcher, J. M. (2006). The cognitive correlates of third-grade skill in arithmetic, algorithmic computation, and arithmetic word problems. Journal of Educational Psychology, 98, 29-43.

Fuson, K. (1988). Children's counting and concepts of number. New York: Springer.

Gaupp, N., Zoelch, C., \& Schumann-Hengsteler, R. (2004). Defizite numerischer Basiskompetenzen bei rechenschwachen Kindern der 3. und 4. Klassenstufe. Zeitschrift für Pädagogische Psychologie, 18, 31-42.

Geary, D.C. (1993). Mathematical disabilities: Cognitive, neuropsychological, and genetic components. Psychological Bulletin, 114, 345-362.

Geary, D. C., Brown, S. C., \& Samaranayake, V. A. (1991). Cognitive addition: A short longitudinal study of strategy choice and speed-of-processing differences in normal and mathematically disabled children. Developmental Psychology, 27, 787-797.

Geary, D.C., Hamson, C.O., \& Hoard, M.K. (2000). Numerical and arithmetical cognition: A longitudinal study of process and concept deficits in children with learning disability. Journal of Experimental Child Psychology, 77, 236-263.

Geary, D.C., \& Hoard, M.K. (2001). Numerical and arithmetical deficits in learning-disabled children: Relation to dyscalculia and dyslexia. Aphasiology, 15, 635-647.

Geary, D.C., Hoard, M.K., Byrd-Craven, J., \& DeSoto, M.C. (2004). Strategy choices in simple and complex addition: contributions of working memory and counting knowledge for children with mathematical disability. Journal of Experimental Child Psychology, 88, 121-151.

Geary, D.C., Hoard, M.K., Byrd-Graven, J., Nugent, L., \& Numtee, C. (2007). Cognitive Mechanisms underlying achievement deficits in children with mathematical learning disability. Child Development, 78, 1343-1359.

Gersten, R., Jordan, N.C., \& Flojo, J.R. (2005). Early identification and interventions for students with mathematics difficulties. Journal of Learning Disabilities, 38, 293-304.

Hecht, S.A., Torgesen, J.K., Wagner, R.K., \& Rashotte, C.A. (2001). The relations between phonological processing abilities and emerging individual differences in mathematical computation skills: A longitudinal study from second to fifth grades. Journal of Experimental Child Psychology, 79, 192-227.

Huntley-Fenner, G., \& Cannon, E. (2000). Preschooler's magnitude comparisons are mediated by a preverbal analog mechanism. Psychological Science, 11, 147-152.

Jordan, N.C., Kaplan, D., Locuniak, M.N., \& Ramineni, C. (2007). Predicting first-grade math achievement from developmental number sense trajectories. Learning Disabilities Research and Practice, 22, 36-46.

Koponen, T., Aunola, K., Ahonen, T., \& Nurmi, J.-E. (2007). Cognitive predictors of single-digit and procedural calculation skills and their covariation with reading skill. Journal of Experimental Child Psychology, 97, 220-241.

Krajewski, K. (2008). Vorschulische Förderung mathematischer Kompetenzen. In F. Petermann \& W. Schneider (Eds.), Enzyklopädie der Psychologie, Reihe Entwicklungspsychologie, Bd. Angewandte Entwicklungspsychologie (pp. 275-304). Göttingen: Hogrefe.

Krajewski, K., Liehm, S., \& Schneider, W. (2004). Deutscher Mathematiktest für zweite Klassen (DEMAT 1+). Göttingen: Beltz.

Krajewski, K., \& Schneider, W. (in press), Early development of quantity to number-word linkage as a precursor of mathematical school achievement and mathematical difficulties: Findings from a four-year longitudinal study, Learning and Instruction (2008), doi:10.1016/ j.learninstruc.2008.10.002

Landerl, K., Bevan, A., \& Butterworth, B. (2004): Developmental dyscalculia and basic numerical capacities: A study of 8-9-year old students. Cognition, 93, 99-125.

Leather, C. V., \& Henry, L. A. (1994). Working memory span and phonological awareness tasks as predictors of early reading ability. Journal of Experimental Child Psychology, 58, 88-111.

Lee, K., Ng, S.-F., Ng, E.-L., \& Lim, Z.-Y. (2004). Working memory and literacy as predictors of performance on algebraic word problems. Journal of Experimental Child Psychology, 89, 140-158.

Lemaire, P., Abdi, H., \& Fayol, M. (1996). The role of working memory resources in simple cognitive arithmetic. European Journal of Cognitive Psychology, 8, 73-103.

Lemer, C., Dehaene, S., Spelke, E., \& Cohen, L. (2003). Approximate quantities and exact number words: dissociable systems. Neuropsychologia, 41, 1942-1958. 
Lenhard, W., \& Schneider, W. (2006). Ein Leseverständnistest für die Elementarschule (ELFE 1-6). Göttingen: Hogrefe.

Logie, R. H., Gilhooly, K. J., \& Wynn, V. (1994). Counting on working memory in arithmetic problem solving. Memory and Cognition, 22, 395-410.

Lundberg, I., Frost, J., \& Peterson, O. (1988). Effects of an extensive program for stimulating phonological awareness in preschool children. Reading Research Quarterly, 23, 263-284.

Milner, B. (1971). Interhemisphere differences in the localization of psychological processes in man. British Medical Bulletin, 27, 272-277.

Mix, K. S., Huttenlocher, J., \& Levine, S. C. (1996). Do preschool children recognize auditory-visual numerical correspondences? Child Development, 67, 1592-1608.

Mix, K. S., Huttenlocher, J., \& Levine, S. C. (2002). Numerical abstraction in infants: Another look. Developmental Psychology, 33, 423-428.

Okamoto, Y., \& Case, R. (1996). Exploring the microstructure of children's central conceptual structures in the domain of number. Monographs of the Society for Research in Child Development, 61, 27-59.

Passolunghi, M.C., \& Siegel, L.S. (2004). Working Memory and access to numerical information in children with disability in mathematics. Journal of Experimental Child Psychology, 88, 348-367.

Passolunghi, M.C., Vercelloni, B., \& Schadee, H. (2007). The precursors of mathematics learning: Working memory, phonological ability and numerical competence. Cognitive Development, 22, 165-184.

Rammelaere, S. D., Stuyven, E., \& Vandierendonck, A. (2001). Verifying simple arithmetic sums and products: Are the phonological loop and the central executive involved? Memory and Cognition, 29, 267-273.

Rasmussen, C., \& Bisanz, J. (2005). Representation and working memory in early arithmetic._Journal of Experimental Child Psychology, 91, 137-157.

Resnick, L. B. (1989). Developing mathematical knowledge. American Psychologist, 44, 162-169.

Rousselle, L., Palmers, E., \& Noël, M.-P. (2004). Magnitude comparison in preschoolers: What counts? Influence of perceptual variables. Journal of Experimental Child Psychology, 87, 57-84.

Schneider, W. (2009). The development of reading and spelling: Relevant precursors, developmental changes, and individual differences. In W. Schneider \& M. Bullock (Eds.), Human development from early childhood to early adulthood: Findings from a 20 year longitudinal study (pp. 199-220). Mahwah, NJ: Erlbaum.

Schneider, W., Küspert, P., Roth, E., Visé, M., \& Marx, H. (1997). Short- and long-term effects of training phonological awareness in kindergarten: Evidence from two German studies. Journal of Experimental Child Psychology, 66, 311-340.

Schneider, W., \& Näslund, J.C. (1999). The impact of early phonological processing on reading and spelling in school: Evidence from the Munich Longitudinal Study. In F.E. Weinert \& W. Schneider (Eds.), Individual development from 3 to 12: Findings from the Munich Longitudinal Study (pp. 126-147). Cambridge, UK: Cambridge University Press.

Schneider, W., Roth, E., \& Ennemoser, M. (2000). Training phonological skills and letter knowledge in children at risk for dyslexia: A comparison of three kindergarten training programs. Journal of Educational Psychology, 92, 284-295.

Schuchardt, K., Kunze, J., Grube, D., \& Hasselhorn, M. (2006). Arbeitsgedächtnisdefizite bei Kindern mit schwachen Rechen- und Schriftsprachleistungen. Zeitschrift für Pädagogische Psychologie, 20, 261-268.

Seitz, K., \& Schumann-Hengsteler, R. (2002). Phonological loop and central executive processes in mental addition and multiplication. Psychologische Beiträge, 44, 275-302.

Simmons, F. R., \& Singleton, C. (2008). Do weak phonological representations impact on arithmetic development? A review of research into arithmetic and dyslexia. Dyslexia, 14, 77-94.

Simmons, F., Singleton, C., \& Horne, J. K. (2008). Brief Report - Phonological awareness and visual-spatial sketchpad functioning predict early arithmetic attainment: Evidence from a longitudinal study. European Journal of Cognitive Psychology, 20, 711-722.

Simon, T.J., Hespos, S.J., \& Rochat, P. (1995). Do infants understand simple arithmetic? A replication of Wynn (1992). Cognitive Development, 10, 253-269.

Starkey, P., \& Cooper, R.G. (1980). Perception of numbers by human infants. Science, 210, 1033-1035.

Stern, E. (1997). Early training: who, what, when, why, and how? In M. Beishuizen, K.P.E. Gravemeijer, \& E.C.D.M. van Lieshout (Eds.), The role of contexts and models of mathematical strategies and procedures (pp. 239-253). Culemborg: Technipress.

Stern, E. (1999). Development of Mathematical Competencies. In F.E. Weinert, \& W. Schneider (Eds.), Individual Development from 3 to 12: Findings from the Munich Longitudinal Study (pp. 154-170). Cambridge: Cambridge University Press.

Stock, C., \& Schneider, W. (2008). Deutscher Rechtschreibtest für das erste und zweite Schuljahr (DERET 1+2). Göttingen: Hogrefe.

Swan, D., \& Goswami, U. (1997). Picture naming deficits in developmental dyslexia: The phonological representation hypothesis. Brain and Language, 56, 334-353.

Swanson, H.L. (2006). Cognitive processes that underlie mathematical precociousness in young children. Journal of Experimental Child Psychology, 93, 239-264. 
Swanson, H., \& Beebe-Frankenberger, M. (2004). The relationship between working memory and mathematical problem solving in children at risk and not at risk for serious math difficulties. Journal of Educational Psychology, 96, 471-491.

Swanson, H.L., \& Howell, M (2001). Working Memory, short-term memory, and speech rate as predictors of children's reading performance at different ages. Journal of Educational Psychology, 93, 720-734.

Thomas, J., Zoelch, C., Seitz-Stein, K., \& Schumann-Hengsteler, R. (2006). Phonologische und zentral-exekutive Arbeitsgedächtnisprozesse bei der mentalen Addition und Multiplikation bei Grundschulkindern. Psychologie in Erziehung und Unterricht, 53, 275-290.

von Aster, M., Schweiter, M., \& Weinhold-Zulauf, M. (2007). Rechenstörungen bei Kindern: Vorläufer, Prävalenz und psychische Symptome. Zeitschrift für Entwicklungspsychologie und Pädagogische Psychologie, 39, $85-96$.

Wagner, R.K., \& Torgesen, J.K. (1987). The nature of phonological processing and its causal role in the acquisition of reading skills. Psychological Bulletin, 101, 192-212.

Weißhaupt, S., Peucker, S., \& Wirtz, M. (2006). Diagnose mathematischen Vorwissens im Vorschulalter und Vorhersage von Rechenleistungen und Rechenschwierigkeiten in der Grundschule. Psychologie in Erziehung und Unterricht, 53, 236-245.

Wilson, J.T.L., Scott, J.H., \& Power, K.G. (1987). Developmental differences in the span of visual memory for pattern. British Journal of Developmental Psychology, 5, 249-255.

Wolf, M. (1984). Naming, reading and the dyslexias: A longitudinal overview. Annals of Dyslexia, 34, 87-115.

Wynn, K. (1992). Addition and subtraction by human infants. Nature, 358, 749-750.

Xu, F., Spelke, E.S., \& Goddard, S. (2005). Number sense in human infants. Developmental Science, 8, 88-101. 